\title{
Práticas de integração Família-Escola como Preditoras do Desempenho Escolar de Alunos*
}

\author{
Daniel Rodriguez Colli ${ }^{1}$ \\ ${ }^{1}$ Pontifícia Universidade Católica de São Paulo, \\ SP, Brasil.
}

\author{
Sergio Vasconcelos de Luna ${ }^{1}$ \\ ${ }^{1}$ Pontifícia Universidade Católica de São Paulo, \\ SP, Brasil.
}

\begin{abstract}
Resumo: O presente estudo avaliou o impacto das práticas de integração família-escola no Brasil sobre o desempenho dos alunos, via um modelo estatístico cujas variáveis construídas buscaram representar as práticas de integração analisadas pelas pesquisas brasileiras. Foram utilizados os microdados Saeb de 2011, que possuíam informações de 3.238.506 alunos do $5^{\circ}$ ano do ensino fundamental. Como variável dependente foi utilizado o nível de proficiência adquirido pelos alunos em matemática e língua portuguesa calculado pelo Saeb. As respostas aos questionários do Saeb, dadas pelos alunos, professores e diretores das escolas, foram empregadas para se criarem as variáveis independentes que buscaram representar as práticas: dever de casa, reunião de pais, expectativas da escola em relação aos pais do aluno e as estratégias de comunicação da escola com a família. Via um modelo de regressão múltipla observou-se um efeito positivo das práticas de integração família-escola sobre o desempenho dos alunos. Entretanto, foi também observado que: 1 . certas posturas de cobrança da escola trouxeram efeitos negativos em relação ao desempenho dos alunos. 2. quando os alunos possuíam pais que sabiam ler e escrever, fazer dever de casa produziu maiores resultados do que os alunos que também faziam, mas que possuíam pais que não sabiam ler e escrever.
\end{abstract}

Palavras-chave: Integração família-escola, Nível de proficiência, Saeb.

\section{Impacts of Family-School Integration Practices on Student Performance}

Abstract: The present study evaluated the impact of family-school integration practices on student performance in Brazil. Data used in this research came from the 2011 Saeb microdata, which had information on 3,238,506 students from the 5th year of elementary school. The level of proficiency acquired by students in math and Portuguese language calculated by Saeb was used as dependent variable. The answers to the Saeb questionnaires, given by students, teachers and school principals, were used to create the independent variables that sought to represent the practices: homework, parents' meeting, expectations of the school in relation to the student's parents and the strategies of communication with the family. Using a multiple regression model, a positive effect of family-school integration practices on student performance was observed. However, it was also observed that: 1 . certain school postures and demands had negative effects on student performance. 2. when students had parents who could read and write, homework produced better academic results than in students who also did homework, but who had parents who could not read and write.

Keywords: Family-school integration, Proficiency level, Saeb.

* Agradecemos ao pesquisador da Universidade de São Paulo, Fabio Tadei, que nos auxiliou na importação e formatação das informações dos microdados SAEB para o programa Stata. 


\title{
Prácticas de Integración Familia-Escuela como Predictores del Desempeño Escolar de Alumnos
}

\begin{abstract}
Resumen: El presente estudio evaluó el impacto de las prácticas de integración familia-escuela en Brasil sobre el desempeño de los alumnos. Se utilizaron los microdatos Saeb de 2011, que tenían informaciones de 3.238.506 alumnos del $5^{\circ}$ año de la enseñanza primaria. Como variable dependiente se utilizó el nivel de competencia adquirido por los alumnos en matemáticas y lengua portuguesa calculado por el Saeb. Las respuestas a los cuestionarios del Saeb, dadas por los alumnos, maestros y directores de las escuelas, fueron empleadas para crear las variables independientes que buscaron representar las prácticas: deber de casa, reunión de padres, expectativas de la escuela en relación a los padres del alumno y las estrategias de comunicación de la escuela con la familia. En un modelo de regresión múltiple se observó un efecto positivo de las prácticas de integración entre la familia y la escuela sobre el desempeño de los alumnos. Sin embargo, también se observó que: 1. ciertas posturas de cobro de la escuela trajeron efectos negativos en relación al desempeño de los alumnos. 2. cuando los alumnos poseían padres que sabían leer y escribir, hacer el deber de casa produjo mayores resultados que los alumnos que también lo hacían, pero que poseían padres que no sabían leer y escribir.
\end{abstract}

Palabras clave: Integración familia-escuela, Nivel de competencia, Saeb.

\section{Introdução}

Mundo afora, são muitas as publicações que buscam identificar o efeito de práticas de integração família-escola sobre a aprendizagem do aluno. Pesquisas norte-americanas evidenciam que o elo entre família e escola, quando bem feito, consegue elevar o desempenho de alunos, independentemente de sua situação econômica ou social (Henderson \& Mapp, 2002). Práticas de integração família-escola elevaram as notas, as habilidades e a frequência escolar dos alunos. As escolas de sucesso mostraram ser importante reconhecer e respeitar as necessidades da família, buscando ter uma relação de confiança na colaboração, em que o poder e as responsabilidades são divididos de maneira igualitária (Henderson \& Mapp, 2002; Clarke, Sheridan, \& Woods, 2010; Reschly, \& Christenson, 2012). É de extrema importância que a escola também reconheça as dificuldades vividas pela família. Restrição de tempo, crenças culturais, falta de conhecimento e entendimento sobre questões educacionais e questões ligadas à exclusão e descriminação são barreiras da família que precisam ser superadas.

No Brasil, não é extenso o número de publicações analisando a temática integração família-escola, sendo em sua quase totalidade compostas por pesquisas empregando apenas análises qualitativas. Aparentemente, a falta de pesquisas com análises quantitativas não impediu que conseguíssemos abordar com profundidade aspectos importantes sobre as práticas de integração família-escola no nosso país. Entretanto, até hoje, não foi possível quantificar a eficácia destas práticas. Mesmo que não saibamos ao certo suas origens, hoje em dia é possível observar que esta ideia está fortemente disseminada em nossa sociedade, inclusive fazendo parte da Lei de Diretrizes e Bases da Educação Nacional (LDB) e do Estatuto da Criança e do Adolescente (ECA). Carvalho (2004) justifica esta tendência, pelo fato de que tal política gera concordância imediata.

Primeiramente, família e escola são identificadas como os dois principais meios responsáveis pelo desenvolvimento do aluno. A ideia de fazer com que estes meios interajam de alguma maneira, com o objetivo de beneficiar o aluno, mostra, à primeira vista, contar com poucos argumentos contrários. Além disso, quando a família se aproxima da escola, esta tende a ser vista como mais democrática. No Brasil, as principais formas de integração família-escola são: acompanhamento dos pais na lição de casa, comparecimento às reuniões de pais e mestres e uma atenção aos comunicados escola-casa (Carvalho, 2004). 
Entretanto, as pesquisas brasileiras mostram que os resultados dessa integração são baixos. Como foi constatado nas pesquisas norte-americanas, práticas de integração família-escola devem levar em conta diversos fatores para que os resultados possam aparecer. Uma vez que as escolas tenham internalizado os pressupostos de como lidar com os mais distintos formatos e perfis de famílias, os efeitos da integração família-escola mostram-se positivamente significativos.

As análises das pesquisas brasileiras evidenciam que, no Brasil, a escola mostrou seguir um modelo de integração família-escola que não leva em conta a heterogeneidade das famílias (Carvalho 2000, 2004; Ribeiro \& Andrade, 2006). Ao invés de se adaptar aos mais distintos formatos de família e à grande disparidade social e cultural presente no Brasil, a escola culpa as famílias que não se encaixam no seu modelo de família ideal, denominando-as de famílias deficitárias (Szymanski, 2004).

Ribeiro e Andrade (2006) identificaram que os pais que conseguiram se encaixar no que era esperado pela escola eram elogiados. O perfil destes pais foi homogêneo, adequando-se à concepção de família ideal, onde o pai é o provedor financeiro e a mãe se dedica aos cuidados do filho e às tarefas domésticas. Os pais que não conseguiram se ajustar ao modelo esperado pela escola foram criticados, sendo considerados ausentes ou irresponsáveis. Existe também a crítica de que as crianças que mais precisam de ajuda são aquelas cujos pais participam menos. Em nenhum momento, as entrevistas com os professores e diretores mostraram haver algum grau de reflexão sobre os motivos deste afastamento (Ribeiro \& Andrade, 2006).

Chechia e Andrade (2005) identificaram outro aspecto que pode justificar a ausência de comprometimento de pais com filhos que apresentam dificuldades de comportamento ou rendimento escolar. No Brasil, o principal meio de comunicação com os pais é a reunião de pais e mestres. Neste meio, os pais de filhos que apresentam alguma dificuldade acabam sendo expostos perante os outros pais. Tal crítica traz vergonha aos pais e estes, com o tempo, acabam desistindo das reuniões.

Esta constatação impede que a família tenha oportunidades de mudar sua condição de família deficitária, imposta pela escola (Chechia \& Andrade, 2005). Mesmo que os pais compartilhem a visão da escola sobre as dificuldades vividas pela criança, a baixa qualidade nos meios de comunicação entre escola e família impossibilita que ambas consigam incorporar ações conjuntas para resolver o problema (Marcondes, Keila \& Sigolo, 2012; Silveira, Luiza \& Wagner, 2009).

$\mathrm{O}$ último aspecto analisado pelas pesquisas brasileiras que traz barreiras ao processo de integração das famílias com a escola diz respeito à prática lição de casa. Sendo um dos principais meios de interação da família com a escola no Brasil, a lição de casa acaba criando diversas tensões na família (Carvalho, 2000). Isto se deve ao fato de que a escola, ao não levar em conta as diferenças sociais, econômicas e culturais da família, não considera as dificuldades da família em ajudar a criança nesta atividade. Muitas vezes, os pais nem possuem o tempo necessário para ajudar o filho, por ambos trabalharem. Ainda pior, são os casos em que os pais têm baixo nível educacional e, por isso mesmo, não conseguem ajudar os filhos nas tarefas da lição de casa. Tais indicações evidenciam que não levar em conta a heterogeneidade das famílias pode fazer das práticas de integração família-escola mais um elemento que ajude a perpetuar a desigualdade social no Brasil, em que as crianças mais prejudicadas são as que vivem em situação econômica e socialmente desfavorecida.

A constatação das pesquisas norte-americanas, de que é possível elevar o desempenho do aluno via práticas de integração família-escola, independentemente da condição social ou cultural da família, corrobora as observações feitas pelas pesquisas brasileiras segundo as quais o problema das práticas de integração família-escola no Brasil está no não cumprimento de critérios cruciais para seu êxito. É preciso haver mais pesquisas no Brasil que consigam avaliar a eficácia das práticas de integração família-escola e as particularidades que a influenciam. Com um maior entendimento sobre esta temática conseguiremos transformar estes resultados em políticas públicas que ajudem a melhorar ou excluir práticas que apenas ajudam a perpetuar a desigualdade social brasileira.

Em vista destas considerações, esta pesquisa avaliou o impacto das práticas de integração família-escola no Brasil sobre o desempenho dos alunos, via um modelo estatístico cujas variáveis construídas buscaram representar as práticas de integração analisadas pelas pesquisas brasileiras. Uma vez que tais pesquisas evidenciaram um distanciamento da escola à realidade e capacidades da família, buscou-se tam- 
bém criar variáveis que pudessem captar a influência desta questão sobre o desempenho dos alunos.

\section{Método}

Para atingir os objetivos da pesquisa, foi criado, a partir dos microdados Saeb de 2011, um modelo de regressão múltipla para identificar as variáveis que podiam explicar as variações no nível de proficiência atingido pelos alunos do $5^{\circ}$ ano do ensino fundamental naquela avaliação. Os microdados do Saeb de 2011 possuíam informações de 3.238 .506 alunos do $5^{\circ}$ ano do ensino fundamental, provenientes de 128.653 turmas e de 64.812 escolas. Esta amostra abrangeu alunos de escolas federais, estaduais, municipais e privadas de todas as regiões do Brasil.

Como variável dependente, que buscou mensurar a aprendizagem dos alunos, foi utilizado o nível de proficiência obtido pelos alunos em matemática e língua portuguesa calculado pelo Saeb. As variáveis independentes empregadas para explicar as variações no nível de proficiência dos alunos foram divididas em dois grupos: variáveis independentes de interesse e variáveis independentes de controle.

Para a criação das variáveis independentes de interesse do modelo foram utilizadas as respostas aos questionários do Saeb de 2011, dadas pelos alunos, professores e diretores das escolas. Dentro destas variáveis, buscou-se utilizar questões dos questionários que poderiam representar as práticas de integração família-escola. Tais práticas, representadas por estas variáveis, foram: dever de casa, reunião de pais, expectativas da escola em relação aos pais ou responsáveis do aluno e as estratégias de comunicação da escola com a família.

Para ter maior confiança nos resultados das variáveis independentes de interesse deste projeto, ligadas às práticas de integração família-escola, foi necessário buscar nos questionários perguntas que também poderiam explicar as variações no nível de proficiência do aluno, mesmo que estas não fossem diretamente ligadas às práticas de integração família-escola. A inclusão de tais variáveis, denominadas variáveis independentes de controle, foi de extrema importância para garantir uma maior confiabilidade nos resultados adquiridos das variáveis independentes de interesse. Isso se deve ao fato de que, em um modelo de regressão múltipla, as distintas variáveis independentes procuraram explicar as variações da variável dependente de forma simultânea. Ao se incluírem as variáveis independentes de controle no modelo, se alteram todos os demais parâmetros que medem as relações das variáveis independentes de interesse com a variável dependente. Neste caso, também se alteram os coeficientes dos testes de significância de cada variável. Em outras palavras, se não fossem incluídas as variáveis independentes de controle, correr-se-ia o risco de encontrar uma relação/ correlação forte quando deveria ser fraca, encontrar uma relação/correlação fraca quando deveria ser forte ou até mesmo encontrar alguma relação/correlação quando de fato não haveria nenhuma.

Assim, via o método de mínimos quadrados, o modelo de regressão múltipla captou como as variáveis independentes poderiam conjuntamente explicar a proficiência dos alunos. Foram criados dois modelos de regressão múltipla: um com a variável dependente sendo a proficiência em matemática dos alunos e outro com a variável dependente sendo a proficiência em língua portuguesa dos alunos.

\section{Resultados}

Para avaliar a eficácia das práticas de integração família-escola no Brasil, foi preciso encontrar, antes de mais nada, um indicador para mensurar o desempenho dos alunos. O nível de proficiência, disponibilizado pelo Saeb, foi o indicador escolhido para ser a variável que mensurou o desempenho dos alunos. Esta escolha deu maior segurança para este trabalho pelo fato de que este indicador difere de outros que apenas avaliam a nota tirada pelo aluno em uma prova, por exemplo.

Mesmo sendo também um número, o nível de proficiência consegue se diferenciar de outros indicadores de desempenho educacional ao medir as habilidades e competências atingidas pelo aluno. Já uma nota recebida em uma prova, nem sempre consegue mensurar o que foi apreendido pelo aluno. Um aluno pode receber uma nota inferior à de outro, mas ter conquistado habilidades e competências superiores. O objetivo do nível de proficiência calculado pelo Saeb é exatamente minimizar estas distorções.

Tendo confiança de que esta foi a melhor informação disponível, foi criada a variável "proficiência_lp_saeb", que representa os indicadores de proficiência dos alunos do $5^{\circ}$ ano do ensino fundamental em língua portuguesa, e a variável "proficiência_mt_ saeb", que representa os indicadores de proficiência dos alunos do $5^{\circ}$ ano do ensino fundamental em 
matemática. Estas foram as únicas variáveis contínuas de cada modelo.

\section{Criação das variáveis independentes de interesse e controle dos modelos}

Foram criadas 16 variáveis independentes de interesse vindas das respostas aos questionários do aluno, uma variável vinda de três respostas dadas pelo professor e cinco variáveis vindas de respostas aos questionários do diretor. Todas as variáveis independentes de interesse são variáveis discretas dicotômicas, tendo o valor 1 quando se confirmava sua descrição para o aluno e 0 quando não se confirmava sua descrição para o aluno. Segue, no Quadro 1, o resumo das variáveis independentes de interesse criadas a partir das respostas dos alunos e as suas descrições. Segue, no Quadro 2, o resumo das variáveis indepen- dentes de interesse criadas a partir das respostas dos professores e diretores das escolas e suas descrições.

Para garantir maior confiança nos parâmetros das variáveis independentes de interesse dos modelos, foi preciso buscar, dentro dos microdados Saeb 2011, informações sobre outros fatores que pudessem evidenciar forte influência sobre a aprendizagem dos alunos. Como as variáveis independentes de interesse, as variáveis independentes de controle são variáveis discretas dicotômicas, tendo o valor 1 quando se confirmava sua descrição para o aluno e 0 quando não se confirmava essa descrição. Tais variáveis buscaram descriminar a região geográfica da escola do aluno, o tipo de dependência administrativa (Federal, Estadual, Municipal e Privada), formação do professor do aluno e aspectos que poderiam qualificar a infraestrutura da escola.

\section{Quadro 1}

Descrição das variáveis independentes de interesse a partir das respostas dos alunos.

\begin{tabular}{|l|}
\hline \multicolumn{1}{|c|}{ Variável independente e sua descrição } \\
\hline $\begin{array}{l}\text { LCmtSemprePais: Aluno responde que faz sempre ou quase sempre dever de matemática e que ambos os pais } \\
\text { ou responsáveis sabem ler e escrever. }\end{array}$ \\
\hline $\begin{array}{l}\text { LCmtSempreMae: Aluno responde que faz sempre ou quase sempre dever de matemática e que apenas a mãe } \\
\text { ou responsável mulher sabe ler e escrever. }\end{array}$ \\
\hline $\begin{array}{l}\text { LCmtSemprePai: Aluno responde que faz sempre ou quase sempre dever de matemática e que apenas o pai ou } \\
\text { responsável homem sabe ler e escrever. }\end{array}$ \\
\hline $\begin{array}{l}\text { LCmtSemprePaisN: Aluno responde que faz sempre ou quase sempre dever de matemática e que nenhum dos } \\
\text { pais ou responsáveis sabe ler e escrever. }\end{array}$ \\
\hline $\begin{array}{l}\text { LClpSemprePais: Aluno responde que faz sempre ou quase sempre dever de língua portuguesa e que ambos os } \\
\text { pais ou responsáveis sabem ler e escrever. }\end{array}$ \\
\hline $\begin{array}{l}\text { LClpSempreMae: Aluno responde que faz sempre ou quase sempre dever de língua portuguesa e que apenas a } \\
\text { mãe ou responsável mulher sabe ler e escrever. }\end{array}$ \\
\hline $\begin{array}{l}\text { LClpSemprePai: Aluno responde que faz sempre ou quase sempre dever de língua portuguesa e que apenas o } \\
\text { pai ou responsável homem sabe ler e escrever. }\end{array}$ \\
\hline $\begin{array}{l}\text { LClpSemprePaisN: Aluno responde que faz sempre ou quase sempre dever de língua portuguesa e que nenhum } \\
\text { dos pais ou responsáveis sabe ler e escrever. }\end{array}$ \\
\hline ReuniaoPais: Aluno responde que os pais ou responsáveis vão sempre ou quase sempre à reunião de pais. \\
\hline IncentEst: Aluno responde que os pais ou responsáveis o incentivam a estudar. \\
\hline $\begin{array}{l}\text { IncentLC: Aluno responde que os pais ou responsáveis o incentivam a fazer o dever de casa e os trabalhos } \\
\text { da escola. }\end{array}$ \\
\hline IncentLer: Aluno responde que os pais ou responsáveis o incentivam a ler. \\
\hline IncentEsc: Aluno responde que os pais ou responsáveis o incentivam a não faltar às aulas. \\
\hline ConversaEsc: Aluno responde que os pais ou responsáveis conversam com ele sobre o que acontece na escola \\
\hline NTrabalhoDom: Aluno responde que não faz trabalhos domésticos em dias de aula. \\
\hline Computador: Aluno responde que em sua casa possui computador com acesso à internet. \\
\hline
\end{tabular}

Fonte: Elaboração própria com base nos microdados Saeb de 2011. 
Quadro 2

Descrição das variáveis independentes de interesse a partir das respostas dos professores e diretores das escolas.

\begin{tabular}{|l|}
\hline \multicolumn{1}{|c|}{ Variável independente e sua descrição } \\
\hline $\begin{array}{l}\text { CulpFamilia: Professor do aluno responde que os possíveis problemas de aprendizagem dos alunos da série } \\
\text { avaliada são decorrentes do meio em que o aluno vive, do nível cultural dos pais dos alunos e da falta de } \\
\text { assistência e acompanhamento da família nos deveres de casa e pesquisas dos alunos. }\end{array}$ \\
\hline $\begin{array}{l}\text { Abertura: Diretor da escola do aluno responde que os pais dos alunos fazem parte do conselho de sua escola e } \\
\text { que o projeto pedagógico desta escola foi desenvolvido pelos professores, pais e outros servidores, estudantes e } \\
\text { ele mesmo. }\end{array}$ \\
\hline $\begin{array}{l}\text { Comunicado: Diretor da escola do aluno responde que para evitar que os alunos faltem às aulas os pais/ } \\
\text { responsáveis são avisados por comunicação escrita. }\end{array}$ \\
\hline $\begin{array}{l}\text { ConversaRP: Diretor da escola do aluno responde que para evitar que os alunos faltem às aulas os pais/ } \\
\text { responsáveis são chamados à escola para conversar sobre o assunto em reunião de pais. }\end{array}$ \\
\hline $\begin{array}{l}\text { ConversaInd: Diretor da escola do aluno responde que para evitar que os alunos faltem às aulas os pais/ } \\
\text { responsáveis são chamados à escola para conversar sobre o assunto individualmente. }\end{array}$ \\
\hline $\begin{array}{l}\text { EnvCasa: Diretor da escola do aluno responde que para evitar que os alunos faltem às aulas A escola envia } \\
\text { alguém à casa do aluno. }\end{array}$ \\
\hline
\end{tabular}

Fonte: Elaboração própria com base nos microdados Saeb de 2011.

A última variável independente de controle criada foi de extrema importância para o modelo. Como o SAEB não evidencia ter uma amostra representativa perfeita, o que implicaria ter uma participação proporcional de cada tipo de escola e de cada região de forma que fosse igual à proporção brasileira, é oferecida uma variável Peso, que determina o peso que cada aluno analisado deveria ter na amostra para que ela fosse semelhante à da população estudada. Pelo programa estatístico utilizado nesta pesquisa (STATA), é possível utilizar esta variável Peso para controlar a baixa representatividade da amostra disponibilizada pelo Saeb. Feito este último controle, as regressões em matemática e língua portuguesa estavam prontas para serem analisadas.

\section{Análise das variáveis independentes de interesse}

As primeiras variáveis independentes de interesse analisadas buscaram identificar o papel do dever de casa sobre a proficiência dos alunos de $5^{\circ}$ ano do ensino fundamental. Com o objetivo de captar também como o viver em famílias cujos pais sabiam ou não ler e escrever poderia afetar esta prática de integração família-escola, foram incluídas neste quesito as respostas dos alunos à pergunta sobre se seus pais ou responsáveis sabiam ler e escrever. Criadas as quatro variáveis para o modelo em matemática (LCmtSemprePais, LCmtSempreMae, LCmtSemprePai e $\mathrm{LCmtSemprePaisN}^{1} \mathrm{e}$ as outras quatro variáveis para o modelo em língua portuguesa (LClpSemprePais, LClpSempreMae, LClpSemprePai e LClpSemprePaisN), o coeficiente encontrado para cada variável mensurou o quanto os alunos que faziam sempre ou quase sempre dever de casa e que possuíam uma das quatro distinções de capital cultural da família (ambos os pais ou responsáveis saberem ler e escrever, apenas a mãe ou responsável mulher saber ler e escrever, apenas o pai ou responsável homem saber ler e escrever e ambos os pais ou responsáveis não saberem ler e escrever) evidenciavam proficiência maior do que alunos que faziam de vez em quando, nunca ou quase nunca dever de casa. Seguem, na Tabela 1, os coeficientes encontrados para estas variáveis no modelo em matemática e em língua portuguesa.

Em resumo, fazer dever de casa sempre ou quase sempre produziu um efeito positivo sobre a proficiência dos alunos não importando se os pais ou responsáveis do aluno sabiam ler e escrever. Entretanto, os coeficientes das variáveis mostraram grandes diferenças para os casos em que ambos os pais ou responsáveis sabiam ler e escrever e quando não sabiam fazê-lo.

Observe-se que o valor do coeficiente encontrado, no modelo em língua portuguesa, de fazer sem-

${ }^{1}$ Conferir Quadros 1 e 2 para ver a decodificação dos nomes das variáveis. 
Tabela 1

Resumo para variáveis de dever de casa*.

\begin{tabular}{lcc}
\hline \multirow{2}{*}{ Variável } & Modelo em matemática & \multicolumn{2}{c}{$\begin{array}{c}\text { Modelo em língua } \\
\text { portuguesa }\end{array}$} \\
\cline { 2 - 3 } & Coeficiente & Coeficiente \\
\hline LClpSemprePais/LCmtSemprePais & 14,46071 & 15,22122 \\
LClpSempreMae/LCmtSempreMae & 13,10703 & 14,11256 \\
LClpSemprePai/LCmtSemprePai & 4,869774 & 5,47487 \\
LClpSemprePaisN/LCmtSemprePaisN & 4,380414 & 5,233793 \\
\hline
\end{tabular}

* Coeficientes encontrados devem ser interpretados em relação a alunos que responderam que faziam dever de casa de vez em quando, nunca ou quase nunca.

Fonte: Elaboração própria com base nos microdados Saeb de 2011.

pre ou quase sempre dever de casa para o caso em que ambos os pais sabiam ler e escrever $(14,46071)$ é mais que três vezes o valor do coeficiente encontrado quando ambos não sabiam ler e escrever $(4,389994)$. Para o modelo em matemática, esta diferença é também quase o triplo (15,22122 contra 5,233793). Assim, o mesmo esforço feito por um aluno sobre a prática de integração família-escola Dever de Casa resultou em diferentes capacidades e habilidades adquiridas pelo aluno (nível proficiência) quando se alterou a habilidade de os pais de saberem ler e escrever. Esta constatação dá suporte aos achados de Carvalho (2000) que evidenciou o quanto os pais que possuem baixo nível educacional tinham maiores dificuldades em ajudar os filhos na lição de casa.

Outra constatação importante levantada neste quesito foi que quando apenas a mãe do aluno sabia ler e escrever, o coeficiente encontrado $(13,10703$ para o modelo em matemática e 14,11256 para o modelo em língua portuguesa) foi bem próximo do coeficiente do caso em que ambos os pais sabiam ler e escrever $(14,46071$ para o modelo em matemática e 15,22122 para o modelo em língua portuguesa). Já no caso em que apenas o pai sabia ler e escrever, o coeficiente encontrado $(4,869774$ para o modelo em matemática e 5,47487 para o modelo em língua portuguesa) foi bem próximo do caso em que ambos os pais não sabiam ler e escrever (4,380414 para o modelo em matemática e 5,233793 para o modelo em língua portuguesa). Esta constatação mostrou que, quando a mãe ou mulher responsável sabia ler e escrever, o efeito de fazer sempre ou quase sempre dever de casa foi expressivamente mais alto do que no cenário em que apenas o pai ou homem responsável sabia ler e escrever.
A próxima variável independente de interesse objetivou analisar a prática de integração família-escola Reunião de Pais. A variável ReuniaoPais representou os alunos que responderam que seus pais iam sempre ou quase sempre às reuniões de pais e seus coeficientes encontrados pelo modelo em matemática e em língua portuguesa foram, respectivamente: 4,389994 e 4,383473 . Estes coeficientes mostraram uma relação positiva entre os pais dos alunos irem com frequência às reuniões de pais sobre a proficiência dos alunos. Esperava-se que alunos cujos pais iam sempre ou quase sempre às reuniões de pais obtivessem 4,389994 pontos a mais em matemática e 4,383473 pontos a mais em língua portuguesa do que alunos cujos pais não iam com tal frequência.

A pesquisa de Ribeiro e Andrade (2006) mostrou que, além de ir às reuniões de pais e ajudar os filhos no dever de casa, a escola esperava que os pais passassem para os filhos a importância da aquisição de conhecimento e que estimulassem os filhos a estudar. Cinco variáveis puderam ser criadas para captar, via a percepção do aluno, como reproduzir tais expectativas da escola poderia afetar a proficiência do aluno. Como foi descrito anteriormente na criação das variáveis independentes de interesse do modelo, estas variáveis foram: IncentEst, IncentLC IncentLer, IncentEsc e ConversaEsc.

Antes de começar a analisar os coeficientes encontrados, vale a pena ressaltar que a variável IncentLC, que representou os alunos que possuíam pais que os incentivavam a fazer dever de casa, não passou pelo critério de p-valor menor que $5 \%$ no modelo completo em matemática e precisou ser rejeitada do modelo final em matemática. A Tabela 2 apresenta o resumo dos coeficientes 
Tabela 2

Resumo para variáveis de expectativas da escola*.

\begin{tabular}{lcc}
\hline \multirow{2}{*}{ Variável } & Modelo em matemática & Modelo em língua portuguesa \\
\cline { 2 - 3 } & Coeficiente & Coeficiente \\
\hline IncentEst & 14,49328 & 15,64515 \\
IncentLC & & 1,685634 \\
IncentLer & 6,736767 & 7,880686 \\
IncentEsc & 7,441276 & 7,676918 \\
ConversaEsc & $-4,667543$ & $-4,705906$ \\
\hline
\end{tabular}

* Coeficientes encontrados de cada variável devem ser interpretados em relação a antítese do que representa cada variável. Fonte: Elaboração própria com base nos microdados Saeb de 2011.

encontrados para estas variáveis no modelo em matemática e em língua portuguesa.

O coeficiente da variável IncentEst mostrou que o aluno avaliar que seus pais o incentivavam a estudar deve ter produzido um grande impacto sobre seu desempenho educacional. Esperava-se que um tal aluno obtivesse 14,49328 pontos a mais em matemática e 15,64515 pontos a mais em língua portuguesa do que um aluno que avaliava que seus pais não o incentivavam a estudar. Foi muito interessante notar que a variável IncentEst foi uma das variáveis que obtiveram um dos maiores impactos sobre a proficiência dos alunos dos modelos.

Esta relação foi também positiva para as variáveis IncentLer e IncentEsc, porém, não tão alta como para a variável IncentEst. Esperava-se que um aluno cuja avaliação era a de que seus pais o incentivavam a ler obtivesse uma proficiência 6,736767 pontos a mais em matemática e 7,880686 pontos a mais em língua portuguesa do que um aluno que afirmava que seus pais não o incentivavam a ler. Está mesma análise valeu para a variável IncentEsc.

Já a variável que representou os alunos que relataram que seus pais conversavam com eles sobre o que acontecia na escola, o coeficiente encontrado foi negativo para ambos os modelos. Isso implica que alunos que tinham uma percepção de que seus pais conversavam com eles sobre o que acontecia na escola deveriam apresentar proficiência menor do que alunos que tinham uma percepção contrária. É difícil oferecer, com propriedade, uma explicação para o fato de esta variável ter apresentando coeficientes negativos. Entretanto, foi possível constatar que esta foi a única das variáveis (pergunta) deste quesito que usou a palavra conversar ao invés de incentivar. Uma hipótese que poderia ser testada, embora não tenhamos dados suficientes para sustentá-la, é que conversar sobre o que acontece na escola pode parecer um pouco mais intrusivo na vida do aluno do que as outras variáveis. Esta intrusão poderia ser vista como uma cobrança, podendo levar alunos que se sentiam cobrados, ao invés de incentivados, a possuírem menores níveis de proficiência.

A variável que teve o menor efeito positivo sobre a proficiência do aluno foi a IncentLC. Além de ter apresentando p-valor abaixo de $5 \%$ apenas no modelo em língua portuguesa, esperava-se que um aluno que avaliava que seu pai o incentivava a fazer dever de casa obtivesse apenas 1,685634 ponto a mais na proficiência em língua portuguesa do que um aluno que avaliava que seus pais não o incentivavam.

A mesma hipótese que foi levantada para dar algum sentido ao coeficiente negativo encontrado para a variável ConversaEsc poderia ser usada para tentar entender o porquê de o coeficiente encontrado para IncentLC ter sido tão mais baixo do que para as variáveis IncentEst, IncentLer e IncentEsc no modelo em língua portuguesa e não significativo para o modelo em matemática. Entretanto, novamente, não tínhamos dados suficientes para fazê-lo.

Se tentarmos olhar este fenômeno por outra ótica, resgatando alguns achados das pesquisas analisadas por Henderson e Mapp (2002), de que o aumento na participação dos pais na vida escolar do aluno pode ser causado pelo prévio mau desempenho do mesmo, esta relação poderia ser explicada também pelo fato de que ambas as variáveis IncentLC e ConversaEsc podiam não apenas influenciar a proficiência dos alunos, mas também serem influenciadas pela proficiência. Alunos com mau compor- 
tamento ou com baixo rendimento escolar podiam levar seus pais a imporem mais controle, cobrando o dever de casa ou mesmo tentando conversar sobre o que acontecia na escola. Esta hipótese levaria os alunos que responderam sim a estas perguntas terem mau rendimento escolar antes de os pais começarem a ter tal conduta. Estas são apenas hipóteses para as quais, infelizmente, não tivemos dados suficientes para testar, mas que seriam muito interessantes de serem estudadas em pesquisas futuras.

Outra questão que foi levantada nas pesquisas brasileiras foi o fato de a escola manter um discurso de culpabilização das famílias cujos filhos apresentavam baixo desempenho, desresponsabilizando-se de seu papel ativo sobre este desempenho. Para testar os achados destas pesquisas, foi criada a variável CulpFamilia que buscou identificar o quanto a proficiência dos alunos podia ser afetada pela crença que o professor tinha de que a dificuldade na aprendizagem do aluno era consequência do nível cultural da família, do meio em que o aluno vivia e da falta de assistência e acompanhamento da família nos deveres de casa e pesquisas dos alunos. Os coeficientes encontrados para esta variável foram de $-2,247678$ para o modelo em matemática e $-1,370032$ para o modelo em língua portuguesa.

Embora a magnitude dos coeficientes não tenha sido alta, a relação da variável CulpFamília (alunos que possuíam professor que tinha a crença de que a dificuldade na aprendizagem do aluno era consequência do nível cultural da família, do meio em que o aluno vivia e da falta de assistência e acompanhamento da família nos deveres de casa e pesquisas dos alunos) com a proficiência dos alunos foi negativa. Esta é uma importante constatação pois esperava-se que um aluno cujo professor acreditava que a causa do mau rendimento de seus alunos estava em fatores extraclasse, obtivesse proficiência menor do que um aluno cujo professor não tinha esta crença. Uma hipótese que poderia ser criada a partir desta constatação é a de que quando se assume que a culpa de o aluno não aprender vem da família ou do meio em que ele vive, o professor se isenta da responsabilidade sobre o mau desempenho deste aluno. Acabar com o discurso de culpabilização das famílias pode ser de extrema importância para que os professores possam assumir um papel mais ativo sobre a aprendizagem de alunos que apresentam baixo rendimento escolar.
Para identificar os resultados de uma escola democrática, que buscava ter maior abertura às famílias na gestão e decisão escolar, foi criada a variável Abertura, que analisou os alunos cujos pais faziam parte do conselho de escolas em que estudavam e ajudavam a desenvolver o projeto pedagógico daquelas. O coeficiente encontrado para esta variável foi de 0,5844971 para o modelo em matemática e de 0,6087449 para o modelo em língua portuguesa. Assim, esperava-se que alunos que estudavam em uma escola que os pais faziam parte do conselho e que ajudavam a desenvolver o projeto pedagógico da escola, obtivessem 0,5844971 ponto a mais na proficiência em matemática e 0,6087449 ponto a mais na proficiência em língua portuguesa do que os alunos que estudavam em uma escola cujos pais não faziam parte do conselho e que não ajudavam a desenvolver o projeto pedagógico da escola.

Mesmo que dar abertura aos pais nos processos decisórios escolares tenha mostrado ter relação positiva com a proficiência dos alunos, a magnitude desta relação foi baixa. Esta constatação pode ser interpretada de duas maneiras. Uma foi que dar abertura às famílias nos processos decisórios da escola não produziu um efeito tão forte para elevar a proficiência dos alunos. A outra maneira de analisar esta constatação foi que, quando se perguntou ao diretor da escola se os pais dos alunos participavam do conselho e se ajudavam a desenvolver o projeto pedagógico da escola, em nenhum momento foi possível capturar como eram conduzidas estas práticas. O diretor da escola ter respondido que dava abertura aos pais não nos diz nada quanto à natureza/qualidade desta interação: se ela foi feita com respeito, de uma forma horizontal ou mesmo se as opiniões dos pais foram levadas em conta para a criação do projeto pedagógico da escola. As pesquisas analisadas por Henderson e Mapp (2002) mostraram a importância de tais critérios para que os resultados destas práticas pudessem ser positivos. No entanto, apenas com outros tipos de dados seria possível aprofundar esta questão.

Outro aspecto do processo de integração família-escola que foi levantado pelas pesquisas brasileiras foi em relação às distintas formas empregadas pela escola para acessar a família. Com isso em mente, foram criadas as seguintes varáveis: Comunicado, ConversaRP, ConversaInd, EnvCasa e ConversaAluno. Em comum, todas estas variáveis foram criadas com base na pergunta ao diretor da escola sobre o que a 
escola fazia para que os alunos não faltassem às aulas. Assim a variável Comunidado representou os alunos que estudavam em uma escola cujo diretor respondeu que para evitar que os alunos faltassem às aulas, os pais eram avisados por comunicação escrita, para a variável ConversaRP os pais eram chamados à escola para conversar sobre o assunto em reunião de pais, para a variável ConversaInd os pais eram chamados à escola para conversar sobre o assunto individualmente, para a variável EnvCasa a escola enviava alguém à casa do aluno e para a variável ConversaAluno a escola apenas conversava com o aluno.

Antes de começar a analisar os coeficientes encontrados, foi observado que a variável ConversaAluno não obteve p-valor abaixo de $5 \%$ nos modelos completos e precisou ser rejeitada dos modelos finais. Isso indica que conversar com os alunos para que eles não faltassem às aulas não teve impacto sobre o nível de proficiência atingido por eles. Já a variável que representava as escolas que enviavam alguém para a casa dos alunos apresentou um p-valor abaixo de 5\% apenas no modelo em matemática e teve que ser rejeitada do modelo final em língua portuguesa. A seguir, na Tabela 3, é apresentado o resumo dos coeficientes encontrados para as variáveis que mensuraram distintas formas da escola acessar a família dos alunos.

Foi muito interessante analisar estas constatações. Lembrando os achados de Chechia e Andrade (2005), os pais de alunos que apresentavam mau rendimento se sentiam expostos perante os outros pais quando eram abordados nas reuniões de pais. Como a reunião de pais era um dos principais meios de interação da família com a escola, tais críticas traziam vergonha para os pais que, com o tempo, acabavam desistindo das reuniões. Mesmo não apresentando um coeficiente de alta magnitude, esperava-se que alunos que estudavam em escolas que decidiam chamar os pais para conversar sobre a falta dos alunos nas reuniões de pais obtivessem proficiência em matemática e língua portuguesa menores do que alunos que estudavam em escolas que não adotavam esta medida. Assim, pôde-se concluir que usar a reunião de pais para chamar a atenção dos pais gerou efeitos negativos para os alunos que estudavam em escolas que assim procediam.

Para corroborar ainda mais esta ideia, a variável que teve o maior coeficiente positivo nesta análise, mesmo que com baixa magnitude, foi a ConversaInd. Chamar para conversar individualmente para que os alunos não faltassem às aulas pareceu ser a melhor medida. De fato, nas escolas que a adotavam, os alunos tiveram proficiência maior do que escolas que não a adotavam ou que tinham outra estratégia.

As últimas variáveis independentes de interesse analisadas foram NtrabalhoDom e Computador. Estas foram consideradas variáveis independentes de interesse por estarem diretamente ligadas às práticas de integração família-escola. Em relação à variável NtrabalhoDom, esperava-se que um aluno que não fazia trabalhos domésticos em dia de aula, obtivesse 4,612392 pontos a mais na proficiência em matemática e 3,746342 pontos a mais na proficiência em língua portuguesa do que um aluno que fazia trabalhos domésticos em dia de aula. Para a variável Computador, esperava-se que um aluno que possuía computador com acesso à internet em casa obtivesse uma proficiência 8,088366 pontos a mais em matemática e 7,298222 pontos a mais em língua portuguesa do que um aluno que não possuía computador com acesso à internet. Estas duas variáveis mostraram que viver em um ambiente que estimulou ou que, de certa forma, não pôs barreiras para que o aluno pudesse ter maio-

Tabela 3

Resumo para variáveis de estratégias de comunicação da escola*.

\begin{tabular}{lcc}
\hline \multirow{2}{*}{ Variável } & Modelo em matemática & Modelo em língua portuguesa \\
\cline { 2 - 3 } & Coeficiente & Coeficiente \\
\hline Comunicado & 0,918377 & 0,8128366 \\
ConversaRP & $-2,475815$ & $-2,632134$ \\
ConversaInd & 1,510928 & 1,762971 \\
EnvCasa & 0,8711263 & \\
\hline
\end{tabular}

* Coeficientes encontrados de cada variável devem ser interpretados em relação a antítese do que representa cada variável.

Fonte: Elaboração própria com base nos microdados Saeb de 2011. 
res condições de exercer atividades escolares em casa, gerou efeitos expressivos para a proficiência em matemática e língua portuguesa do aluno.

\section{Considerações finais}

Ao se avaliarem os efeitos de práticas de integração família-escola sobre o nível de proficiência em matemática e língua portuguesa dos alunos do $5^{\circ}$ ano do ensino fundamental, a partir dos microdados SAEB de 2011, constatou-se que os objetivos da pesquisa foram alcançados. O primeiro objetivo foi avaliar o impacto das práticas de integração família-escola no Brasil sobre o desempenho dos alunos. Observou-se que, em geral, as variáveis de interesse criadas para analisar o papel de práticas de integração família-escola sobre a proficiência em matemática e língua portuguesa mostraram uma relação positiva entre elas. Estas variáveis foram: LCmtSemprePais, LCmtSempreMae, LCmtSemprePai, LCmtSemprePaisN, LClpSemprePais, LClpSempreMae, LClpSemprePai, LClpSemprePaisN, NTrabalhoDom, Computador, ReuniaoPais, IncentEst, IncentLer, IncentEsc, ConversaInd, Abertura e Comunicado. Esta constatação corrobora os achados das pesquisas analisadas por Henderson e Mapp (2002), mostrando que, independentemente da região e do capital cultural da família, práticas de integração família-escola produziram efeitos positivos para o aluno. Entretanto, para o cenário brasileiro, alguns pontos importantes foram lançados sobre a execução destas práticas no Brasil.

Mais importante do que incentivar práticas de integração família-escola, temos que garantir que estas sejam pensadas e orquestradas levando em conta as capacidades e realidades vividas pelas famílias brasileiras. O efeito negativo encontrado das variáveis ConversaRP e CulpFamilia, e a disparidade nos resultados das variáveis que mediram fazer dever de casa sempre ou quase sempre dependendo de se os pais ou responsáveis sabiam ler e escrever, mostraram o quanto temos que tomar cuidado na execução destas práticas.

Mesmo que o efeito sobre a proficiência do aluno dos pais irem às reuniões de pais sempre ou quase sempre foi positivo, quando a escola mostrou que a reunião de pais foi um momento de chamar a atenção dos pais, o resultado sobre a proficiência do aluno que estudou em tal escola foi negativo. Ir às reuniões é uma prática importante para ajudar na proficiência do aluno: entretanto, a escola não pode fazer dela um mecanismo de cobrança que envergonhe os pais. Isso mostra que alunos que mais precisavam do fortalecimento desta relação eram os alunos que tiravam menos proveito dela.

Como foi dito anteriormente, mesmo que os pais compartilhem a visão da escola sobre as dificuldades vividas pela criança, a baixa qualidade nos meios de comunicação entre escola e família impossibilita que ambos os meios consigam incorporar ações conjuntas para resolver o problema (Marcondes, Keila \& Sigolo, 2012; Silveira, Luiza \& Wagner, 2009). A escola precisa reconhecer mais distintas formas de famílias e se adaptar a elas para não acabar excluindo aqueles que não se ajustam às práticas de integração família-escola impostas por ela (Ribeiro \& Andrade, 2006).

O segundo objetivo desta pesquisa foi avaliar o impacto do distanciamento da escola à realidade e capacidades da família sobre o desempenho dos alunos. Os dois achados preocupantes desta pesquisa, que ajudaram a atingir este objetivo, foram os resultados encontrados sobre a variável CulpFamilia e sobre as variáveis que mediram a prática Dever de Casa. O primeiro achado, vindo do coeficiente negativo encontrado para a variável CulpFamilia, é que ainda continuamos com o discurso de culpar o meio em que $o$ aluno vive e o capital cultural da família pelo mau desempenho dos alunos. Os resultados indicaram uma expectativa de que os alunos das escolas que mantinham estas crenças tivessem proficiência em matemática e língua portuguesa menor do que a dos alunos que estudavam em escolas que não as mantinham. O segundo achado, vindo da comparação dos coeficientes encontrados para as distintas variáveis que mediram a prática Dever de Casa, é que o rendimento, em termos de aumento de proficiência em matemática e língua portuguesa, de alunos que faziam sempre ou quase sempre dever de casa para alunos cujos pais não sabiam ler e escrever foi um terço do rendimento de um aluno cujos pais sabiam ler e escrever. Ambas constatações evidenciaram o quanto fatores socioeconômicos relacionados à família acabam, mesmo que indiretamente, afetando o desempenho dos alunos.

Em tempos em que se discute muito a implementação de medidas educacionais focadas na meritocracia, como é que nós podemos premiar o esforço do aluno em fazer dever de casa, por exemplo, quando o mesmo esforço leva a resultados distintos, depen- 
dendo do capital cultural da família do aluno? Se as práticas escolares apresentarem os mesmos resultados das práticas de integração família-escola, colocar a meritocracia no meio escolar apenas ajudará a perpetuar a desigualdade social. A educação deveria ser, acima de tudo, um meio para que possamos atingir uma sociedade mais justa e não acentuar as injustiças criadas ao longo de nossa história. É de extrema relevância que novas pesquisas sejam feitas para investigar modos de melhorar ou produzir novas práticas educacionais que garantam que a educação não seja mais um meio que produza desigualdades.

\section{Referências}

Carvalho, M. E. P. (2000). Relações entre família e escola e suas implicações de gênero. Cadernos de Pesquisa, (110), 143-155. https://doi.org/10.1590/S0100-15742000000200006

Carvalho, M. E. P. (2004). Escola como extensão da família ou família como extensão da escola? O dever de casa e as relações família-escola. Revista Brasileira de Educação, (25), 94-104. https://doi.org/10.1590/S141324782004000100009

Chechia, V. A., \& Andrade, A. S. (2005). O desempenho escolar dos filhos na percepção de pais de alunos com sucesso e insucesso escolar. Estudos de Psicologia (Natal), 10(3), 431-440. https://doi.org/10.1590/S1413294X2005000300012

Clarke, B. L., Sheridan, S. M., \&Woods, K. E. (2010). Elements of healthy family-school relationships. In S. L. Christenson, \& A. L. Reschly (Eds.), Handbook of school-family partnerships (pp. 61-79). New York, NY: Routledge.

Henderson, A. T., \& Mapp, K. L. (2002). A new wave of evidence: The impact of school, family, and community connections on student achievement. Austin, TX: Southwest Educational Development Laboratory.

Marcondes, K. H. B., \& Sigolo, S. R. R. L. (2012). Comunicação e envolvimento: Possibilidades de interconexões entre família-escola? Paidéia (Ribeirão Preto), 22(51), 91-99. https://doi.org/10.1590/S0103-863X2012000100011

Reschly, A. L., \& Christenson, S. L. (2012). Moving from "context matters" to engaged partnerships with families. Journal of Educational and Psychological Consultation, 22(1-2) , 62-78. https://doi.org/10.1080/10474412.2011.649650

Ribeiro, D. F., \& Andrade, A. S. (2006). A assimetria na relação entre família e escola pública. Paidéia, 16(35), 385-394.

Silveira, L. M. O. B., \&Wagner, A. (2009). Relação família-escola: Práticas educativas utilizadas por pais e professores. Psicologia Escolar e Educacional, 13(2), 283-291. https://doi.org/10.1590/S1413-85572009000200011

Szymanski, H. (2004). Práticas educativas familiares: A família como foco de atenção psidoeducacional. Estudos de Psicologia (Campinas), 21(2), 5-16. https://doi.org/10.1590/S0103-166X2004000200001

\section{Daniel Rodriguez Colli}

Mestre em Psicologia da Educação pela Pontifícia Universidade Católica de São Paulo (PUC/SP), São Paulo - SP. Brasil.

E-mail: dancolli@hotmail.com

http://orcid.org/0000-0003-3988-6200

\section{Sergio Vasconcelos de Luna}

Professor titular do Depto. de Métodos e Técnicas da Faculdade de Ciências Humanas e da Saúde da Pontifícia Universidade Católica de São Paulo (PUC/SP), São Paulo - SP. Brasil.

E-mail: svluna@uol.com.br

http://orcid.org/0000-0002-3162-8859

Endereço para envio de correspondência:

Sergio Vasconcelos de Luna - Pontifícia Universidade Católica de São Paulo. Rua Ministro de Godoy, $4^{\circ}$ Andar -

Sala 4E-07, Perdizes.

CEP: 05014-901. São Paulo - SP. Brasil. 
Recebido 09/10/2017

Aceito 20/03/2018

Received 10/09/2017

Approved 03/20/2018

Recibido 09/10/2017

Aceptado 20/03/2018

Como citar: Colli, D., \& Luna, S. V. (2019). Práticas de Integração Família-Escola como Preditoras do Desempenho Escolar de Alunos. Psicologia: Ciência e Profissão, 39, 1-13. https://doi.org/10.1590/1982-3703003186361

How to cite: Colli, D., \& Luna, S. V. (2019). Impacts of Family-School Integration Practices on Student Performance. Psicologia: Ciência e Profissão, 39, 1-13. https://doi.org/10.1590/1982-3703003186361

Cómo citar: Colli, D., \& Luna, S. V. (2019). Prácticas de Integración Familia-Escuela como Predictores del Desempeño Escolar de Alumnos. Psicologia: Ciência e Profissão, 39, 1-13. https://doi.org/10.1590/1982-3703003186361 